\title{
A atuação da Cia. de Canetas Compactor no processo de industrialização de Nova Iguaçu (1954-1974)
}

The performance of Cia. de Canetas Compactor in the process of industrialization of Nova Iguaçu

La actuación de la Cia. de Canetas Compactor en el proceso de industrialización de Nova Iguaçu

La performance de la Compagnie de Stylos Compactor dans le processus

d'industrialisation de Nova Iguaçu (1954-1974)

\section{Carolina Bittencourt Mendonça}

\section{(2) OpenEdition}

Journals

Edição electrónica

URL: http://journals.openedition.org/espacoeconomia/3148

DOI: $10.4000 /$ espacoeconomia.3148

ISSN: 2317-7837

\section{Editora}

Núcleo de Pesquisa Espaço \& Economia

Refêrencia eletrónica

Carolina Bittencourt Mendonça, «A atuação da Cia. de Canetas Compactor no processo de industrialização de Nova Iguaçu (1954-1974) », Espaço e Economia [Online], 12 | 2018, posto online no dia 14 julho 2018, consultado o 19 abril 2019. URL : http://journals.openedition.org/ espacoeconomia/3148; DOI : 10.4000/espacoeconomia.3148

Este documento foi criado de forma automática no dia 19 Abril 2019.

(c) NUPEE 


\section{A atuação da Cia. de Canetas Compactor no processo de industrialização de Nova Iguaçu (1954-1974)}

The performance of Cia. de Canetas Compactor in the process of industrialization of Nova Iguaçu

La actuación de la Cia. de Canetas Compactor en el proceso de industrialización de Nova Iguaçu

La performance de la Compagnie de Stylos Compactor dans le processus d'industrialisation de Nova Iguaçu (1954-1974)

\section{Carolina Bittencourt Mendonça}

\section{O contexto da industrialização de Nova Iguaçu}

1 No dia 10 de Junho de 1945, o Correio da Lavoura publicou uma reportagem intitulada "Aspectos da cidade". o texto disserta sobre o desenvolvimento do município de Nova Iguaçu e remete à ideia de avanço a partir "do progresso da indústria e da lavoura" 1 . Apesar da aparência rural da região, sabemos que nos anos 1940 o termo "indústria" já não configurava uma novidade para a Baixada Fluminense. Em Duque de Caxias já havia a Fábrica Nacional de Motores funcionando à todo vapor e impulsionando a instalação de outras indústrias nos anos seguintes, tais como a Química Farmacêutica Proquifar (produtos farmacêuticos), a Sedabel Ltda (vitaminas) e a Sansão Vasconcelos S/A (carroçarias de ferro) ${ }^{2}$. Em Magé, as indústrias têxteis já estavam instaladas desde o final do século XIX, e no início dos anos 1950, com o objetivo de modernizar seu parque fabril, a Companhia América Fabril - que já detinha a, então obsoleta, Fábrica Pau Grande instala uma nova unidade, a Santana (RIBEIRO, 2015, p. 73). 
2 No caso de Nova Iguaçu, mesmo antes da construção da rodovia Presidente Dutra, portanto, antes de 1951, já existiam pequenos e grandes estabelecimentos industriais, localizadas no perímetro urbano do município. As menores, com menos de 20 funcionários, eram maioria - cerca de 34 - e atendiam às necessidades da população próxima, como oficinas, barracões para beneficiamento de laranjas, fábrica de bebidas, laticínios, olarias, fábricas de bolsas, calçados, bonecas, artefatos de cimento, entre outras. As maiores indústrias, com mais de 20 funcionários, configuraram os estabelecimentos que impulsionaram o desenvolvimento de uma zona industrial em Nova Iguaçu. Dentre elas, as principais eram: Cia. Mercantil e Industrial Ingá (metalúrgica), PIAM - Farmacêutica e Comercial do Brasil, Fábrica Universal (fogos), Irmãos Coutinho Cereais, BRASFERRO - Laminação Brasileira de Ferro S.A., Fábrica de Tecidos Caxambi e Mineração Geral do Brasil (SOARES, 1962).

3 Apesar do Fundo Rodoviário Nacional ter sido criado a partir de uma política rodoviarista que possuía objetivos de recuperar a agricultura, em Nova Iguaçu sua atuação, na forma da rodovia Presidente Dutra, acabou contribuindo para o processo de industrialização. A área se mostrou atrativa para o estabelecimento de indústrias pelos seguintes motivos: 1) os valores dos lotes eram consideravelmente menores em relação aos terrenos do perímetro urbano devido à distância do centro do município, e 2) implantar um empreendimento fabril às margens da recém-inaugurada rodovia Presidente Dutra significava uma facilidade no escoamento da produção.

4 Em 1945, quando Nova Iguaçu ainda possuía fortes contornos rurais e vivia a tentativa de recuperação da citricultura, foi criada a Associação Comercial e Industrial de Nova Iguaçu (ACINI), confirmando então que estes estabelecimentos já estavam consolidados e que por isso, necessitavam de uma entidade representativa. Três anos depois, foi concedida a essa associação, via decreto, a prerrogativa do art. 513 da Consolidação das Leis do Trabalho, a fim de colaborar com o poder público como órgão técnico e consultivo, no estudo e solução dos problemas que se relacionassem com os interesses econômicos da região ${ }^{3}$. A ACINI atuava mais intensamente na organização de congressos e encontros com outras entidades representativas, sempre discutindo os rumos da industrialização a partir da perspectiva do empresário e questionando regularmente direitos conquistados pelos trabalhadores e garantidos pelo estado.

5 Embora já houvesse uma classe empresarial estabelecida no município, é a partir da década de 1950 que a ACINI conquista maior representatividade. A atuação do grupo de comerciantes e industriais passa a acontecer com mais frequência, quase sempre voltada para a política iguaçuana em forma de questionamentos acerca de diversos assuntos, como educação, saneamento básico, segurança e, principalmente, impostos. A atuação da ACINI se tornou possível após o desenvolvimento dos estabelecimentos industriais instalados às margens do trecho recém construído da BR-116. A rodovia Presidente Dutra cortou uma área na qual havia uma larga extensão de laranjais, que começaram a ser loteados antes mesmo do fim da citricultura na região. Os loteamentos representavam uma das atividades mais lucrativas da região, principalmente após as obras de saneamento promovidas pelo governo nas primeiras décadas do século XX. Isso refletia "a manutenção de uma economia em que o principal elemento é a terra" (GEIGER; SANTOS, 1954, p. 307).

6 Num primeiro momento os lotes eram anunciados como ideais para estabelecimentos como cinema e teatro, e também para a construção de casas de veraneio destinadas à classe média residente na capital federal ${ }^{4}$. Com o advento da Dutra, o perfil dos 
compradores se transformou. Os empresários interessados em instalar estabelecimentos fabris na região, mas que não conseguiam devido aos altos valores dos lotes mais próximos ao centro e da estação de trem, enxergaram nas proximidades da rodovia Dutra, local mais afastado do centro urbano, a oportunidade ideal para concentrar suas fábricas. Esse período foi então marcado pela chegada de indústrias, que pouco tempo depois, se tornaram estabelecimentos de destaque como a Cia. Dyrce Industrial, Usina Mecânica Carioca, Cia. de Canetas Compactor, Plastin-Indústria e Comércio de Plásticos, Niquifer Indústria e Comércio, Cia. Sotex Técnica de Papéis, Cia. Metalúrgica de Austin, Cia. Pneus General, Probal Indústria e Comércio-Tintas, Tecelagem de Linho Oxford, Bayer do Brasil e Forjas Brasileiras (SOARES, 1962).

7 As dificuldades que a Segunda Guerra gerou nas importações contribuíram para que inúmeras produções industriais fossem protegidas, o que culminou num crescimento da economia e do setor industrial. Nas décadas posteriores ao conflito, o desenvolvimento industrial continuou e o país já produzia a maioria dos bens necessários para suprir o mercado interno. Tem início então o processo de substituição de importações de bens de consumo e produção de bens duráveis, fundamental para o desenvolvimento de uma zona industrial em Nova Iguaçu.

8 Percebemos através das entrevistas realizadas para esta pesquisa, que boa parte dos trabalhadores do bairro Jardim Iguaçu não é natural do Rio de Janeiro. Essa é uma das principais características da população da Baixada Fluminense. A população migrante, com destaque para a maioria de nordestinos, contribuiu diretamente para o crescimento e o desenvolvimento da Baixada Fluminense, especialmente Nova Iguaçu e Duque de Caxias, municípios que sempre figuraram entre os mais populosos do estado do Rio de Janeiro.

9 Nos dispusemos a refletir sobre as migrações para a Baixada Fluminense, uma vez que a tendência predominante no país era de fluxos migratórios em direção às regiões urbanas, por isso, o destaque das duas maiores cidades do sudeste, Rio de Janeiro, inicialmente Distrito Federal, e São Paulo. A reflexão vale pelo fato da Baixada Fluminense, apesar de já inserida no processo de desenvolvimento industrial, representar à primeira vista uma região predominantemente rural, com uma área verde consideravelmente maior do que a área urbanizada, além de oferecer menores oportunidades de trabalho em comparação à metrópole vizinha.

10 No entanto, havia a necessidade de uma região que pudesse proporcionar uma ampliação da área urbana da capital fluminense. Dessa forma, Rodrigues (2006) assinala:

Nesse período, a cidade do Rio de Janeiro necessitava de áreas próximas para promover sua expansão. Seriam áreas de terrenos baratos e servidos por transporte para abrigar a população de trabalhadores que para ela afluía, e que era atraída pela expansão do mercado de trabalho na capital (RODRIGUES, 2006, p. 61)

11 A população que migrou para São Paulo foi em busca de uma remuneração melhor e de uma maneira mais fácil de conseguir empregos (FONTES, 2008). Se, por um lado, os migrantes de São Paulo conseguiram se estabelecer na cidade que concentrava cerca de $50 \%$ dos empregos em indústrias do país, por outro, uma parte da massa que migrou em direção à cidade do Rio de Janeiro encontrou dificuldades para se estabelecer no local devido à alta valorização das terras cariocas.

12 Nesse contexto, os municípios da Baixada Fluminense, como Nova Iguaçu, se aproveitaram da situação para facilitar o estabelecimento dessa população migrante que não conseguia se fixar no Rio de Janeiro. Assumindo a alcunha de cidade-dormitório, a 
prefeitura de Nova Iguaçu exerceu o seu papel para que não houvesse impedimento para que essas pessoas se firmassem no município, facilitando as construções de tipo proletário, além de clandestinas (SOARES, 1962, p. 185).

13 Comparando os dados entre os Censos Demográfico e Econômico de 1950, percebemos que num primeiro momento, efetivamente, essa população que se estabeleceu em Nova Iguaçu estava em sua maioria empregada fora da região. No ano de 1950, residiam em Nova Iguaçu 3.696 empregados do comércio e 13.878 operários de indústrias. Entretanto, apenas 1.550 e 3.216 desses trabalhadores estavam, respectivamente, empregados no município. Tais dados demonstram, por certo, o caráter de cidade-dormitório do município iguaçuano. No universo das fábricas que já havia se instalado na região, era de fato indiscutivelmente pequeno o número de estabelecimentos que empregavam mais de 100 operários.

14 Na década seguinte essa situação começa a se transformar. $\mathrm{O}$ aumento desenfreado dos loteamentos nos anos $1950^{5}$ contribuiu para que na década seguinte mais indústrias se estabelecessem em terras iguaçuanas. Somando-se este fato ao constante aumento do fluxo migratório para a região, temos a equação ideal para os empresários: possibilidade de contratar uma mão-de-obra predominantemente local e oferecer salários mais baixos que os pagos na capital, e em algumas situações com total desrespeito aos direitos trabalhistas.

Considerando que, além dos industriários, Nova Iguaçu ainda possuía pessoal ocupado nos estabelecimentos comerciais; na pecuária, uma vez que esta atividade rendeu cerca de $\mathrm{Cr} \$$ 4,3 milhões em produção de leite e abate de gado; nas lavouras, onde a laranja e a banana ainda dominavam a produção com um rendimento de $\operatorname{Cr} \$ 3,4$ milhões; e em outras categorias como servidores públicos, transportes, educação e bancos, é, portanto, possível vislumbrar uma classe trabalhadora razoavelmente consolidada na região e bastante diversificada.

\section{A Cia. de Canetas Compactor}

16 A criação da Compactor no Brasil está inserida na relação entre dois empresários alemães, Reynaldo Bluhm e Paul Buschle. O primeiro era proprietário de editora e livraria no Brasil, e revendia canetas tinteiro como artigos de luxo. Do outro lado, Buschle possuía uma pequena fábrica de canetas tinteiro em Wuppertal, na Alemanha. O primeiro acordo entre os empresários consistiu em trazer para o Brasil uma remessa das canetas Compactor, para testar se havia a possibilidade de concorrer com as canetas americanas e europeias com marcas já consolidadas. A distribuição deu certo e o segundo acordo firmado entre Bluhm e Buschle teve como principal objetivo produzir a caneta em solo brasileiro. Em 1954 é formada a sociedade entre Reynaldo Bluhm, Paul Buschle, Erich Buschle e Adolfo Nieckele e a Cia. de Canetas Compactor é criada. ${ }^{6}$

17 O próximo passo foi a aquisição do terreno e o início da construção do parque industrial. A região onde a fábrica está localizada, o bairro Jardim Iguaçu no município de Nova Iguaçu, era uma área de grandes laranjais, na qual foi se transformando com o passar dos anos em uma região com um desenho cada vez mais industrial e menos rural, especialmente pela inauguração da Rodovia Presidente Dutra (BR-116). o parque fabril foi então instalado às margens da rodovia e passou a servir como referência nas vendas dos terrenos mais próximos. Percebemos pelos classificados dos jornais cariocas, que a região 
já estava sendo tratada como zona industrial e a Cia. de Canetas Compactor estava sempre presente nos anúncios como atração.

O terreno na Rodovia Presidente Dutra no Km 181 foi adquirido em 1954, local ideal dentro dessa conjuntura de desenvolvimento da industrialização visto que, construir uma fábrica próxima à uma grande rodovia seria fundamental para o deslocamento da produção.

19 Na transação de compra dos terrenos foram adquiridos dois lotes, um ao lado do outro. Portanto, a empresa já estaria preparada para aumentar o complexo fabril, caso fosse necessário. O complexo demorou cerca de um ano para ficar pronto e por isso, a produção começou somente no ano de 1955. Nesse intervalo de tempo as canetas vindas da Alemanha continuavam a ser comercializadas pelo Rio de Janeiro fortalecendo a presença da marca.

20 As obras de construção do complexo já se encontravam no fim e o momento era o ideal para começar a compor o quadro de funcionários. Como consequência da intensa migração do Norte e Nordeste que contribuiu para o aumento da população da Baixada Fluminense, mesmo que não tão intensa como no caso da região metropolitana de São Paulo, o município de Nova Iguaçu naquele momento já possuía uma oferta de mão de obra. No entanto, não bastava ter braços para o trabalho se eles não eram qualificados. Por isso, assim como ocorreu na Bayer do Brasil, funcionários alemães vieram para compor o quadro inicial de funcionários (CARVALHO, 2015). No caso da Compactor, os funcionários que chegaram da Alemanha eram técnicos reconhecidos como "jovens talentos" em sua região, e tinham como objetivo ensinar o trabalho para os operários recém-contratados. O quadro de funcionários foi composto de forma bem diversificada, com brasileiros e alemães; homens e mulheres, jovens e pessoas mais velhas. No entanto, ao longo das entrevistas, percebemos que a relação entre alemães e brasileiros durante um certo período não se deu de forma tão pacífica como citado no periódico, veremos essa questão mais à frente.

21 Durante os primeiros anos da fábrica o serviço era apenas de montagem, posto que as matérias-primas ainda não eram fabricadas no Brasil. No ano da construção do complexo fabril os maquinários foram importados e nos anos seguintes, já com a produção funcionando, as matérias-primas ainda eram importadas. Até os anos 1960 os materiais continuaram sendo importados e, portanto, a atividade na fábrica ainda se manteve basicamente como montagem de canetas tinteiro - a produção das esferográficas começaria somente na década seguinte. Por isso, o quadro de funcionário nos primeiros anos possuía uma quantidade pequena de trabalhadores. Miriam da Rocha Azeredo conta que quando ingressou na fábrica para trabalhar no almoxarifado, em 1957, havia 17 funcionários no total. Na década seguinte a fábrica atingiu cerca de 140 funcionários. ${ }^{7}$ As duas primeiras décadas de funcionamento da fábrica testemunharam ao aumento da produção da empresa, desenvolvida com a presença cada vez mais intensa do patrão Buschle, que almejava colocar em prática seu projeto paternalista como estratégia de dominação dos trabalhadores.

O desenvolvimento da Cia. de Canetas Compactor foi consideravelmente rápido para uma indústria que começou pequena, como pioneira no ramo das canetas-tinteiro no Brasil, e se deu em paralelo com à aceleração do crescimento industrial do Brasil. As políticas promovidas pelo governo de Juscelino Kubitschek com o objetivo de estabelecer uma economia industrial madura contribuíram diretamente para que as indústrias que se 
estabeleceram pouco antes do início do seu mandato presidencial pudessem se beneficiar desse impulso.

No ano de 1960, a Compactor, que começara em 1955 com uma capacidade de produção de dez mil unidades mensais, é obrigada a expandir seu maquinário para produzir trinta vezes mais do que o inicialmente planejado. Considerando-se que, conforme descrito acima, já haviam naquele momento outras marcas de canetas consolidadas no Brasil, essa ampliação indica que os produtos da Compactor haviam conseguido obter boa aceitação por parte do consumidor brasileiro. Desse modo, a filial brasileira superava, em muito, a fábrica localizada na Alemanha. Na avaliação dos dirigentes da empresa, relatada à imprensa no período, tal sucesso se deveria à pesquisa de mercado que a empresa fizera antes de começar suas atividades. 0 objetivo era produzir uma caneta de acordo com o que o mercado consumidor demandava, com um custo de aquisição mais baixo do que o das importadas e rentabilidade maior. Essa proposta ficou registrada em um slogan publicitário que ficou famoso na época: "Duas vezes mais tinta!". Para comemorar seu quinto aniversário de atividades, a fábrica vira a década com uma produção anual de um milhão de unidades. ${ }^{8}$

24 Alguns fatores muito importantes contribuíram para o sucesso de produção da fábrica no início dos anos de 1960. Primeiramente, o custo da produção diminuiu consideravelmente, pois a fábrica não precisava mais importar a matéria-prima para produzir as canetas. Na década de 1960 todos os componentes já eram fabricados em solo brasileiro. $O$ segundo ponto importante é a política de atender as demandas do consumo brasileiro. A Compactor intensificou a produção das linhas de canetas tinteiro Escolar, Super-Escolar e Universitária, que custavam menos que os modelos mais elegantes de canetas, e por isso vendiam mais. 0 último fator que fez com que a Compactor alcançasse um sucesso absoluto foi a introdução no mercado brasileiro de um produto inovador, a caneta esferográfica, com o lançamento daquele que seria o maior sucesso de vendas da companhia, a Compactor 0.7. ${ }^{9}$

Além dessa consolidação da marca Compactor no mercado interno, a década de 1960 foi marcante para a empresa pelo desenvovimento da capacidade de produção dos componentes necessários para a montagem das canetas. Com isso ela deixou de depender de importações e ampliou sua capacidade de criação de novos modelos de canetas, o que também fortalecia sua capacidade de atender às demandas de um mercado nacional em expansão, seu principal objetivo desde o início da produção. Essa prosperidade da Cia. de Canetas Compactor se inseria em um momento histórico no qual a indústria de canetas como um todo deu um salto à frente. Conforme a coluna sobre negócios de Oswaldo Lopes, no periódico Última Hora:

Segundo os últimos dados estatísticos, a produção de canetas fabricadas no Estado do Rio está tendo um acelerado incremento, com a ampliação da capacidade das unidades industriais existentes e utilização em tempo quase integral do equipamento instalado. Destinadas até mesmo à exportação, as canetas fluminenses rendem bons impostos à União e ao

Estado, além de a respectiva indústria dar trabalho a centenas de operários. (Última Hora, 28/12/1963)

Com o falecimento de Paul Buschle em 1968, a manutenção da fábrica na Alemanha tornou-se inviável, e ela fechou as portas dois anos depois. Extinta a antiga matriz, o filho, Dieter Buschle, vem para o Brasil e se incorpora à Cia. de Canetas Compactor como engenheiro chefe da oficina mecânica, tornando-se rapidamente, diretor técnico da 
companhia presidida por se tio Erich Buschle. Dieter herdou do pai o ofício, e chegou a inventar alguns modelos inovadores de canetas e lapiseiras, inaugurando assim

uma nova fase na Cia. de Canetas Compactor. Durante a década de 1970, a partir das ideias de seu novo diretor técnico, a companhia aprimorou a produção das esferográficas e passou a investir mais diretamente na produção de utensílios escolares, como canetas hidrográficas coloridas e lapiseiras. Tudo isso sem deixar de lado a produção das canetas tinteiro, que embora estivessem perdendo mercado, ainda representavam um importante artigo da empresa. Com isso, a Cia. de Canetas Compactor continuava a prosperar, como ocorria com boa parte das indústrias instaladas na Baixada Fluminense no mesmo período.

Durante os anos 1960 e 1970 a fábrica aumentou suas vendas e sua produção, consolidando-se como uma grande indústria brasileira situada na Baixada Fluminense. Paralelamente a esse crescimento da empresa, iniciou-se a construção da ideia de "família Compactor", projeto paternalista idealizado por Erich Buschle, com o objetivo de manter os trabalhadores sob as rédeas do patrão. Num primeiro contato com a realidade da empresa, nos pareceu que esse projeto de paternalismo industrial havia sido posto em prática plenamente e conquistado seus objetivos. No entanto, ao analisarmos as estruturas das relações de trabalho da empresa e o papel dos trabalhadores no seu interior, percebemos como a "família Compactor" era frágil.

A Cia. de Canetas Compactor completou recentemente 60 anos de atividades. Por ter permanecido ao longo de todos esses anos produzindo no mesmo local, a fábrica construiu uma relação muito particular com o bairro que se formou ao seu redor, e em muitas ocasiões os dois se misturam no imaginário dos moradores. Os exemplos dessa simbiose vão desde a escandalosa sirene que sinaliza as trocas de turnos na fábrica e marca o passar do tempo no dia-a-dia do local, ao fato do nome do bairro ser desconhecido por boa parte da população de Nova Iguaçu que insiste em chamá-lo de "Compactor", como o fazem os próprios moradores. Outro forte sinal no mesmo sentido é o fato de nomes relacionados à fábrica estarem presentes por todo o espaço do bairro: praça Paul Bluhm, Escola Compactor, Alameda Paul Buschle. De acordo com José Sergio Leite Lopes (1988) em seu estudo sobre a cidade fabril de Paulista, em Pernambuco,

0 vigor de uma forma de dominação pode ser avaliado por sua interiorização pelo próprio grupo dominado. Para além dos símbolos objetivados que o patronato local imprimiu às fábricas e à cidade - como por exemplo a Fábrica Arthur, nome de um dos patrões; a Igreja Santa Elizabeth, toda construída pela companhia em homenagem à matriarca da família patronal; o busto ao coronel Frederico (irmão de Arthur e filho de Elizabeth) no pátio da monumental Casa Grande - estão os símbolos escolhidos pelos trabalhadores locais quando compõem uma história incorporada ao seu grupo social, e que dão sentido e vida à forma específica de dominação a que estiveram submetidos a maior parte de suas vidas. (LOPES, 1988, p. 32)

Embora a sociedade da Cia. de Canetas Compactor tenha sido formada por quatro homens, sendo apenas dois deles da mesma família, a figura do patrão sempre foi exercida pelos Buschle, principalmente pelo irmão mais novo Erich Buschle. Acreditamos que o principal motivo dessa função ter sido atribuída a Erich Buschle foi sua presença física no bairro. 0 empresário morou exatos sessenta anos na mesma casa no Jardim Iguaçu. Sempre frequentou intensamente todos os lugares de sociabilidade do bairro: festas de rua, igreja, centro comercial. Mas o local em que essa presença era mais marcante, até porque diária, era nas diferentes seções da fábrica. 
31 A política assistencialista tem início em 1956, quando a empresa promoveu a contratação de um médico e uma enfermeira para realizar um trabalho de saúde preventiva. A exfuncionária Miriam Azeredo relata que a assistência era bem básica, visto que a produção ainda era muito pequena e a fábrica possuía poucos funcionários. $O$ benefício era apenas para os funcionários, mas como durante os primeiros anos de funcionamento da fábrica praticamente todos eles residiam no bairro, as consultas atendiam boa parte da população da região. À medida em que a Compactor ia se desenvolvendo, a população da região ia aumentando, e num determinado momento os profissionais contratados não eram mais suficientes para atender a todos.

Percebemos, no caso da Compactor, que o bairro Jardim Iguaçu carecia de qualquer forma de assistência pública ou privada. Portanto, durante a década seguinte, a empresa intensificou o assistencialismo inaugurado timidamente nos anos 1950. A compra do terreno para construção da fábrica contava com uma área despovoada no entorno para que fossem feitas as expansões à medida que se tornassem necessárias. Nos anos 1960, começam as obras que contribuiriam para disseminar a imagem de Erich Buschle como um patrão benfeitor: "a família Compactor pode se orgulhar de representar um dos grupos de operários industriais mais homogêneos e categorizados do país."10

33 A primeira construção realizada na área de três hectares que a Cia. de Canetas Compactor adquiriu após a sua fundação foi uma creche completa para os filhos dos funcionários, no início da década de 1960. A creche funcionava no local que, posteriormente, seria construída a Igreja de São Pedro e São Paulo, no conjunto habitacional também criado pela empresa. Em Junho de 1963, foi inaugurada a Escola Municipal Canetas Compactor, o primeiro estabelecimento de ensino primário promovido por uma firma industrial, produto de um convênio entre a empresa e a Prefeitura Municipal de Nova Iguaçu. A escola foi instalada em terreno e prédio próprio da Compactor, ao lado da fábrica, com 120 alunos matriculados. A escola ofertava matrículas prioritárias para filhos de empregados e mantinha vagas extensivas às crianças residentes no bairro e proximidades.

Esta área de três hectares adquirida logo após a fundação da fábrica primeiramente serviu para a construção da creche e da escola. Em 1964, no que restou do terreno foi construído uma tímida vila, com cercas e portões, que continha apenas duas dezenas de casas destinadas a alguns funcionários da fábrica. Essas habitações seguiam a hierarquia presente dentro do parque industrial da Compactor e eram destinadas aos chefes de seção, contramestres e técnicos, excluindo qualquer operário subalterno de ter oportunidade a esse benefício. Classificamos esse primeiro conjunto de um projeto "tímido" porque a pretensão da fábrica era a construção de algo muito maior, com mais habitações, que pudesse contemplar cada vez mais operários e seus familiares, e que ao mesmo tempo consolidasse aquela região como "bairro Compactor" no imaginário da população.

Porém, um projeto tão ambicioso e pretensioso como esse não poderia acontecer de forma tão rápida. Portanto, ao longo dos primeiros anos de atividade do parque industrial, a Compactor adquiriu estrategicamente diversos terrenos na região, visando construções futuras. Além disso, também comprou diretamente dos proprietários algumas pequenas casas, que eram oferecidas aos funcionários que não tinham casa própria ou que não moravam nas proximidades, mediante o pagamento de um aluguel descontado em folha, como no caso de Ana, que teve a oportunidade de morar por um longo período de tempo em uma residência da Compactor, pois seu marido era motorista da fábrica. No entanto, quando se encontrou viúva, não quis continuar com o benefício, visto que naquela família 
já não havia nenhum funcionário da Compactor. ${ }^{11}$ Esse apontamento nos mostra como o benefício deveria ser usufruído apenas enquanto o beneficiado fosse funcionário da fábrica. Romildo, o esposo falecido, residiu com sua família em casas da Compactor mediante desconto mensal em seu holerite até falecer. A entrevistada nos confidenciou que, embora à época tivesse um bom relacionamento com Erich Buschle, jamais aceitaria morar de favor na casa, com a justificativa de que não ficaria satisfeita em criar uma dívida com o antigo patrão do marido: "Vai que ele pede pro meu filho trabalhar lá?"

O sucesso de uma indústria instalada em uma região até então pouco urbanizada como a Baixada Fluminense contribuiu para fortalecer duas ideais bastante difundidas na região durante o período. A primeira era de que o "progresso" estava chegando à região de Nova Iguaçu. A segunda de que qualquer mudança estrutural no bairro Jardim Iguaçu se devia à Compactor. O primeiro pensamento foi - e ainda é - amplamente propagado por trabalhadores e moradores do bairro. A frase "A Compactor levou o nome de Nova Iguaçu para o resto do Brasil!" está presente em todas as conversas e entrevistas realizadas durante nossa pesquisa.

37 Num domingo de setembro de 1964 o Jornal do Brasil editou um suplemento especificamente para o município de Nova Iguaçu e o dedicou à Compactor, em função do grande sucesso de vendas que a companhia vinha obtendo. O periódico afirmava, de forma bastante ufanista, que "as mais belas páginas da história da evolução industrial do Brasil, inegavelmente, foram escritas por empresas como a Compactor."

Quando o Conjunto Habitacional Compactor - que teve seu projeto de 178 casas produzido pelo engenheiro Adolfo Nieckele, sócio da empresa e membro da diretoria naquele momento - foi inaugurado em 1970, os Buschle acreditaram que tal acontecimento seria a cereja do bolo da família Compactor, visto que, após esse período, nenhum outro benefício tão significativo veio a ser implantado. $\mathrm{O}$ financiamento da iniciativa ficou por conta do Banco Nacional de Habitação, e a Compactor cedeu o amplo terreno para a construção do conjunto "dotado de praças de recreação, ruas amplas, escola para 300 alunos e 178 residências." (Revista Iguaçu-News. Ano II, n. 19, agosto de 1970).

Essa parceria entre a Compactor e o Banco Nacional de Habitação, assim como o convênio do município de Nova Iguaçu com a fábrica para a construção da Escola Compactor, nos mostra como as políticas sociais promovidas pela fábrica, embora tenham sido direcionadas de forma prioritária para seus funcionários, não atingiram somente aos trabalhadores. Diferentemente do clássico modelo de vila operária construída pela fábrica para os operários, o Conjunto Habitacional Compactor contemplou qualquer pessoa que pudesse arcar com o financiamento de um imóvel próprio. No entanto, como no caso da escola, os funcionários tiveram prioridade no processo de aquisição. Mas, empregados na fábrica ou não, os compradores recebiam as casas prontas com escritura e um financiamento de 15 anos, com um valor equivalente a dez por cento do salário mínimo do período. Alguns anos após a inauguração do conjunto, o BNH leiloou abertamente em Nova Iguaçu 41 casas do conjunto com o objetivo de pagar a dívidas hipotecárias contraídas pelos proprietários.

Inicialmente poderia parecer que esse tipo de parceria da Compactor com o Estado fosse uma espécie de novidade no universo das políticas sociais empresariais brasileiras. No entanto, embora não seja tão usual, Telma de Barros Correia (2003) nos mostra como a partir dos anos de 1920 o subsídio estatal, não apenas para a implantação de fábricas (isenções fiscais), mas também para construção de núcleo fabris e vilas operárias passou a 
ocorrer com mais frequência. Essa "atuação" do Estado em parceria com indústrias se deu de diversas formas.

41 Acreditamos que o caso da Cia. de Canetas Compactor se encaixe na concepção de que o Estado se absteve em relação à prestação de serviços básicos e, portanto, a parceria entre Estado e empresa:

(...) fazia-se pela omissão do primeiro, na medida em que os detentores de cargos públicos não costumavam impedir a indústria de "fazer leis" válidas nos limites de seu núcleo fabril, impondo regulamentos - referentes a uso dos espaços coletivos, ao consumo, às normas de conduta, à circulação e ao uso do tempo - e punições aos que os infringissem. (CORREIA, 1998, p.3)

42 A ideia de omissão do Estado se mostra de forma clara quando, na primeira década de funcionamento da fábrica, as primeiras intervenções no Jardim Iguaçu são feitas pela Compactor: a Associação Atlética, a creche, o pequeno conjunto com 12 casas e a construção de um centro comercial. Tais ações contribuíram para a construção de uma memória, que hoje se encontra enraizada, de que a família Buschle foi a responsável pela transformação do bairro de região rural para região urbanizada. Mesmo que as edificações mais importantes tenham sido construídas através de parcerias com o município de Nova Iguaçu, no caso da escola, e com o Governo Federal, no caso do conjunto habitacional.

43 A política social assistencialista promovida por uma instituição industrial deve ser problematizada, analisada de forma mais profunda, e compreendida como um mecanismo de dominação, dentro de um sistema de paternalismo industrial onde a fábrica trata a questão do controle da mão de obra como algo essencial para o andamento do processo produtivo. Essas políticas visam ao aumento da produtividade, baseado na viabilização de melhores condições de vida para seus empregados, o que reforça o discurso ideológico capitalista, ao fortalecer a ideia de que a fábrica está provendo os benefícios que o próprio governo não fornece. Nesse contexto, à medida que as fábricas eram instaladas às margens da rodovia Presidente Dutra e conquistavam algum progresso produtivo, iam se apropriando da vizinhança, na tentativa de construir um clássico sistema paternalista, adaptado à realidade regional. ${ }^{12}$

44 No entanto, nosso objetivo não é cair nas garras de uma análise simplista do sistema paternalista, que reduza a participação do trabalhador como mero "aceitador" do sistema, sugerindo sua imobilidade ou passividade. Para fundamentar uma análise mais complexa e consistente do fenômeno do paternalismo, partimos da reformulação da teoria das classes sociais proposta por Savage (2004):

o traço distintivo da vida operária não se apoia exclusivamente no processo de trabalho (como frisaram os marxistas) nem no mercado de trabalho (como desejariam os weberianos), mas na insegurança estrutural vivida por todos os trabalhadores. (SAVAGE, 2004, p. 33)

O autor também chama atenção para a importância de analisarmos o cotidiano da vida operária, compreendendo a rotina de incertezas e insegurança estrutural em que o trabalhador está inserido.

Desse ponto de vista, todo o espaço do bairro deve ser analisado de forma profunda, particularmente aspectos tão importantes quanto a rotina do trabalho, o cotidiano da vizinhança e os espaços de lazer. A insegurança estrutural a que o operário da Compactor esteve submetido, com ausência de serviços básicos para sobrevivência como saneamento, 
saúde, educação e lazer, influenciou diretamente na sua resposta frente à postura paternalista da fábrica.

47 Nos propusemos neste artigo a apontar brevemente a atuação da Cia. de Canetas no processo de industrialização de Nova Iguaçu, região marcada economicamente pelo próspero período da citricultura. A ênfase de nossa pesquisa foi nas primeiras décadas de funcionamento da fábrica, cujo período representa o maior crescimento da empresa e o início das transformações que ocorreram no bairro onde a fábrica está instalada. Constatamos que a Compactor possui um papel significativo no processo de industrialização iguaçuana, no que diz respeito a construção de uma cultura operária, e sobretudo na atuação dos Buschle nas organizações empresariais e políticas do município. $\mathrm{E}$, por isso, temos a aspiração de continuarmos essa pesquisa buscando analisar intrinsecamente a relação entre esses empresários e a sociedade iguaçuana.

\section{BIBLIOGRAFIA}

CARVALHO, Maicon Sérgio Mota. A greve da Bayer Belford Roxo: Ascensão e crise de uma indústria multinacional na Baixada Fluminense (1958-1989). Dissertação de Mestrado. Universidade Federal Rural do Rio de Janeiro - Instituto de Ciências Humanas e Sociais Programa de Pós-graduação em História. 2015.

CORREIA, Telma de Barros. Estado e empresas na criação e gestão de vilas operárias e núcleos fabris: parcerias, cooperação e conflitos. Anais do X Encontro Nacional da Anpur: Cidade, planejamento e gestão urbana: história das idéias, das práticas e das representações. Belo Horizonte, 2003.

CORREIA, Telma de Barros. Núcleo fabril X cidade livre: os projetos urbanos da Klabin do Paraná. Anais do V Seminário de História da Cidade e do Urbanismo. Campinas, PUC, 1998.

FONTES, Paulo. Um Nordeste em São Paulo: Trabalhadores migrantes em São Miguel Paulista (1945-1966). Rio de Janeiro: Editora FGV, 2008.

FORTES, Alexandre. Nós do Quarto Distrito. A classe trabalhadora porto-alegrense e a Era Vargas. Caxias do Sul: Educs, 2004.

FURTADO, Cristiane Silva. Tecendo as Redes do Paternalismo: lazer, identidade entre os trabalhadores da fábrica Paracambi (1874-1918). Dissertação de Mestrado. Pontífica Universidade Católica - PUC. Rio de Janeiro, 2012.

GEIGER, Pedro Pinchas; SANTOS, Ruth Lyra. Notas sôbre a Evolução da Ocupação Humana na Baixada Fluminense. Revista Brasileira de Geografia, Rio de Janeiro, ano XVI, n. 3, julhosetembro, 1954.

LOPES, José Sérgio Leite Lopes. A tecelagem dos conflitos de classe na cidade das chaminés. São Paulo: Editora Marco Zero, 1988.

MELLO, Juçara da Silva Barbosa de. Fios da Rede: industrial e trabalhadores na criação e expansão de um grupo empresarial (1920-1949). Tese de Doutorado. Pontífica Universidade Católica do Rio de Janeiro - PUC. Rio de Janeiro, 2012. 
PEREIRA, Waldick. Cana, café e laranja: história econômica de Nova Iguaçu. Rio de Janeiro: FGV/ SEEC, 1977.

PERROT, Michelle. Os excluídos da história: operários, mulheres e prisioneiros. Rio de Janeiro: Paz e Terra, 2010.

RAMALHO, José Ricardo. Estado-Patrão e luta operária: O caso FNM. Rio de Janeiro: Paz e Terra, 1989.

RIBEIRO, Felipe Augusto dos Santos. A foice, o martelo e outras ferramentas de ação política: os trabalhadores rurais e têxteis de Magé (1956-1973). Tese de Doutorado. Fundação Getúlio Vargas - Centro de Pesquisa e Documentação de História Contemporânea do Brasil/CPDOC. Rio de Janeiro, 2015

RODRIGUES, Adrianno Oliveira. De Maxambomba à Nova Iguaçu (1833-90's): Economia e território em processo. Dissertação de Mestrado. Universidade Federal do Rio de Janeiro - Programa de Pós-Graduação em Planejamento Urbano e Regional, 2006.

SAVAGE, Mike. Classe e história do trabalho. In: BATALHA, Claudio H. M.; SILVA, Fernando Teixeira; FORTES, Alexandre. (orgs.) Cultura de classe: identidade e diversidade na formação do operariado. Campinas: Editora da Unicamp, 2004, p. 33.

SOARES, M. T. de Segadas. Nova Iguaçu - Absorção de uma célula urbana pelo grande Rio de Janeiro. Revista Brasileira de Geografia. Ano XXIV, n. 2, abril-junho de 1962.

\section{NOTAS}

1. Correio da Lavoura, 10/06/1045.

2. Coleção de Monografias № 446. Fundação IBGE - Instituto Nacional de Estatística. Rio de Janeiro, 1968.

3. Jornal do Brasil, 20/06/1948.

4. Jornal do Brasil, 04/04/1948 e 05/10/1950; Correio da Manhã, 10/06/1949.

5. Tabela demonstrativa com dados que informam que o número de lotes em Nova Iguaçu na década de 1950 teve um aumento de 6,5 vezes comparado com a década anterior, configurando 166.816 lotes somente no município de Nova Iguaçu. Disponível em RODRIGUES, op. cit.

6. Para uma análise mais profunda sobre a imigração das famílias Bluhm e Buschle ver MENDONÇA, Carolina Bittencourt. "Família Compactor": A trajetória da Cia. de Canetas Compactor e a relação com os trabalhadores no processo de industrialização de Nova Iguaçu nos anos 1950, 1960 e 1970. Dissertação de Mestrado em História. Programa de Pós-Graduação em História, Universidade Federal Rural do Rio de Janeiro, 137p., 2017.

7. Entrevista com Miriam da Rocha Azeredo e José Américo de Azeredo, concedida à autora em Dezembro de 2015.

8. Correio da Manhã, 19/06/1960.

9. Última Hora, 11/03/1963.

10. Correio da Manhã, 19/06/1960.

11. Entrevista de Ana Maria dos Santos Lopes concedida à autora, em 03/07/2015.

12. Para compreender melhor as relações entre fábrica e trabalhadores na Baixada Fluminense conferir: RAMALHO, José Ricardo. Estado Patrão e Luta Operária: o caso FNM. São Paulo: Paz e Terra, 1989; CARVALHO, Maicon Sérgio Mota. A greve da Bayer Belford Roxo: ascensão e crise de uma indústria multinacional na Baixada Fluminense (1958-1989). 2015. Dissertação de Mestrado. Universidade Federal Rural do Rio de Janeiro - Instituto de Ciências Humanas e Sociais. RIBEIRO, Felipe Augusto dos Santos. A foice, o martelo e outras ferramentas de ação política: os 
trabalhadores rurais e têxteis de Magé (1956-1973). Tese de Doutorado. Fundação Getúlio Vargas - Centro de Pesquisa e Documentação de História Contemporânea do Brasil/CPDOC. Rio de Janeiro, 2015; MELLO, Juçara da Silva Barbosa de. Fios da Rede: industrial e trabalhadores na criação e expansão de um grupo empresarial (1920-1949). Tese de Doutorado. Pontífica Universidade Católica do Rio de Janeiro - PUC. Rio de Janeiro, 2012; FURTADO, Cristiane Silva. Tecendo as Redes do Paternalismo: lazer, identidade entre os trabalhadores da fábrica Paracambi (1874-1918). Dissertação de Mestrado. Pontífica Universidade Católica - PUC. Rio de Janeiro, 2012.

\section{RESUMOS}

Este trabalho tem como objetivo analisar a atuação da Cia. de Canetas Compactor no processo de industrialização do município de Nova Iguaçu, localizado na Baixada Fluminense. Buscamos demonstrar o contexto inicial da industrialização iguaçuana, os desdobramentos da instalação da fábrica, a relação com os trabalhadores e as transformações que a região sofreu no processo, incluindo aumento populacional e modificações urbanas. Utilizamos como fontes entrevistas realizadas com trabalhadores ativos e aposentados, periódicos e documentos oficiais do IBGE.

The objective of this work is to analyze the performance of Cia. de Canetas Compactor (pen factory) in the process of industrialization of the municipality of Nova Iguaçu, located in the Baixada Fluminense. We sought to demonstrate the initial context of the industrialization of the plantations, the unfolding of the factory, the relationship with the workers and the transformations that the region suffered in the process, including population increase and urban modifications We used as sources interviews with active and retired workers, periodicals and official IBGE documents.

Este trabajo tiene como objetivo analizar la actuación de la Cia. de Canetas Compactor (fábrica de bolígrafos) en el proceso de industrialización del municipio de Nova Iguaçu, localizado en la Baixada Fluminense. Buscamos demostrar el contexto inicial de la industrialización iguaçuana, los desdoblamientos de la instalación de la fábrica, la relación con los trabajadores y las transformaciones que la región sufrió en el proceso, incluyendo aumento poblacional y modificaciones urbanas. Utilizamos como fuentes entrevistas realizadas con trabajadores activos y jubilados, periódicos y documentos oficiales del IBGE.

L'objectif de ce travail est d'analyser la performance de la Compagnie de Stylos Compactor dans le processus d'industrialisation de la municipalité de Nova Iguaçu, situé dans la Baixada Fluminense. Nous avons cherché à démontrer le contexte initial de l'industrialisation de Nova Iguaçu, le déroulement de l'usine, les relations avec les travailleurs et les transformations subies par la région, y compris l'augmentation de la population et les modifications urbaines. Nous avons utilisé comme sources des interviews avec des travailleurs actifs et retraités, des périodiques et des documents officiels de l'IBGE. 
ÍNDICE

Mots-clés: Industrialisation; Compagnie de Stylos Compact; travailleurs; Nova Iguaçu

Keywords: Industrialization; Cia. de Canetas Compactor; Nova Iguaçu; workers.

Palabras claves: Industrialización; Cia. de Canetas Compactor; Nova Iguaçu; trabajadores.

Palavras-chave: Industrialização; Cia. de Canetas Compactor; Nova Iguaçu; trabalhadores.

\section{AUTOR}

\section{CAROLINA BITTENCOURT MENDONÇA}

Mestre em História pela Universidade Federal Rural do Rio de Janeiro

Email: bittcarolina@gmail.com 